\title{
The Key Role of Packing Technique for Successful Endoscopic Repair of CSF Rhinorhea
}

\author{
WAEL A. ALZAMIL, M.D. \\ The Department of Ear Nose and Throat, Hearing and Speech Institute, General Organization for Teaching Hospitals and \\ Institutes, Egypt
}

\begin{abstract}
Background: Spontaneous CSF leaks are rare, their diagnosis is often delayed, and they can precipitate meningitis. Craniotomy and intracranial approach is the historical "gold standard" repair for these leaks [1]. Anendonasal endoscopic approach offers potentially less invasiveness and lower surgical morbidity than a traditional craniotomy but must yield the same surgical success [2]. Recurrence of these leaks is not uncommon. One of the most important factors of this recurrence is inadequate support of the flaps or grafts or loose cooptation of raw surfaces which may be unable to resist the normotensive CSF leak. Maintaining adequate continuous low grade pressure intraoperativelyand two weeks postoperatively may optimize the best chance for raw areas to heal properly with minimal recurrence.
\end{abstract}

Aim of Study: The aim of this study is to identify and discuss the pivotal role of intraoperative packing and its technique to obtain a successful repair of CSF rhinorrhea.

Patients and Methods: A prospective randomized study conducted on 14 patients suffering spontaneous CSF rhinorrhea, from March 2018 to April 2020 in Hearing and Speech Institute. The 14 patients have been divided into two equal groups 7 patients each, group A and group B. In group A, traditional nasal packing was done, whoever, in group B, the special packing was done in the form two packs, the first pack over the grafted area was two layered composed of $1 \mathrm{~mm}$ thickness silasticsheet over the graft and raw area and a piece of Merocel 1 by $1.5 \mathrm{cmms}$ supporting the silastic sheet. The second pack was placed in the nasal cavity. The first pack has been changed weekly to two or three weeks then removed finally.

Results: All patients were doing well throughout the follow-up period. In group A, there was recurrence in fourpatients, two after six months and two after one year. In group B there was one recurrence after one year of follow-up.

Correspondence to: Dr. Wael A. Alzamil, The Department of Ear Nose and Throat, Hearing and Speech Institute, General Organization for Teaching Hospitals and Institutes, Egypt
Conclusion: Intraoperative special packing over the grafted area and regular pack changing post-operatively by the same technique to offer a low grade potential energymay be essential to obtain the required sustained pressure over the grafted areaand maximizes the healing process and adhesions minimizing the recurrence of CSF leak.

Key Words: CSF rhinorrhea packing - Potential energy pack.

\section{Introduction}

CEREBROSPINAL Fluid (CSF) leaks are generally classified as traumatic, iatrogenic, and spontaneous/idiopathic. Traumatic causes include both blunt and penetrating facial injuries. Iatrogenic causes include neurosurgical and otolaryngologic approaches to neoplastic disease, as well as Functional Endoscopic Sinus Surgery (FESS) [3] . Some cases of spontaneous, or primary CSF rhinorrhea are now thought actually to be secondary to elevations in Intracranial Pressure (ICP) that might be seen in patients with Idiopathic Intracranial Hypertension (IIH). Congenital skull base defects and certain tumors can also lead to CSF rhinorrhea [4]

A literature review by Lobo et al., indicated that in addition to increased ICP, risk factors for spontaneous CSF leaks include obesity, female gender, and obstructive sleep apnea. In his study, about $72 \%$ of patients with spontaneous CSF leaks were female, and about $45 \%$ had obstructive sleep apnea [5].

Benign Intracranial Hypertension $(\mathrm{BIH})$ is a disease of the brain. Benign intracranial hypertension is characterized by increased pressure in the brain without any evidence of any brain pathology by imaging studies. Also characterised by normal cerebrospinal fluid content. 
It is known by different names, including Idiopathic Intracranial Hypertension (IIH) and Pseudotumourcerebri (PTC) [6] .

Spontaneous Cerebrospinal Fluid (CSF) rhinorrhea represents an important clinical entity that is being observed with increasing prevalence, ranging from 14 to $55 \%$. Because spontaneous CSF rhinorrhea may be due to elevated Intracranial Pressure (ICP), so many investigations should be exhausted before endoscopic repair to exclude intracranial hypertension and to avoid recurrence. These investigations include fundus examination and C.T. or M.R.I. brain with neurological consultation. Lumber drain with direct manometry of the CSF pressure is rarely used except in recurrent cases which are usually due to benign increase in CSF tension even with normal pre-operative investigations. So proper endoscopic repair with competent flaps and grafts are mandatory to resist the normal CSF pressure until healing process to be complete. Recurrence after competent endoscopic repair needs a battery of investigations to exclude intracranial hypertension because revision surgery may fail without additional CSF diversion surgery or shunting techniques $[7,8]$.

\section{There are essentials for successful repair:}

1- Identification of the defect or defects.

2- Creation of raw area around the defect (by denuding mucosa from nderlying bone.

3- Precise adjustment of the graft or rotation flap over the defect plus or minus sealing the dural tear by fat or facia.

4- Applying adequate pressure over the flap or the graft to resist and overcome the normal CSF pressure.

There are two main mechanisms of sealing, the first is tucking the facial graft or fat under the bony edges of the defect or fitting fat in the dural tear by insinuation whoever the dura is usually thin and adherent to bone of skull base which may result in more dural trauma during the process of tucking and insinuation leading to weak sealing. The second is application of a free graft or rotation vascularized flap over the defect and the surrounding bare bone. In this mechanism the application should exert pressure equal or more than the normal CSF pressure to stop leak. Usually there is combination of both mechanisms.

We may be unable to guarantee the first mechanism alone. Also unable to guarantee the second mechanism without adequate pressure, so we should combine both mechanisms plus application of adequate pressure to optimize sealing and to Salvage the possible weak first mechanism.

From a physical point of view, for a graft or flap to stop a normotensive CSF leak, it needs to exert a static potential energy or force equal or more than CSF pressure. That is correct in most cases where the graft was put on lay but not necessary if the graft was put underlay tucking it under the edges of the bony defect all around which is a difficult duty and also should be augmented by an on lay graft or flap to salvage a possible unnoticed defect. So, again being an on lay graft it must exert a potential energy or force equal or more than CSF pressure to stop any leak. Any graft or flap when fill the dead space and takes the shape of this space will exert nearly zero force at its periphery, whoever if this graft was pushed by an expanding pack (its size is bigger than the space) like sponge ormerocel, so it will exert a potential force sufficient to overcome the normal CSF pressure preventing its leak.

\section{Subjects and Methods}

Ethics: We have obtained a written informed consent from each patient accepting to participate in the study according to and approved by the Institutional Ethical Committee.

Subjects: A prospective randomized study conducted on 14 patients suffering spontaneous CSF rhinorrhea from March 2018 to April 2020 in Hearing and Speech Institute. The 14 patients have been divided into two equal groups 7 patients each, group $\mathrm{A}$ and group $\mathrm{B}$. In group $\mathrm{A}$, traditional nasal packing was done, whoever, in group $\mathrm{B}$, the special packing was done.

Selection criteria: Patients with recent history of Spontaneous leak with proved normal intracranial tension.

Exclusion criteria: Excluded from the study all post-operative and posttraumatic CSF leaks, recurrent cases and patients with evidence of increased intracranial tension. Patients with BMI $>40 \mathrm{~kg} / \mathrm{m}^{2}$ being a significant risk factor.

Methods: Prospective randomized study.

Pre-operative assessment: Detailed history taking and physical examination to confirm the diagnosis of spontaneous CSF leak in the form of unilateral watery salty nasal drip with no history 
of trauma or nasal surgery. This drip occasionally increases with straining or leaning forward or on awakening (reservoir sign). Nasal endoscopy, C.T cysternography or M.R. cysternography to localized the skull base defect.

Fundus examination and C.T. or M.R.I. brain with neurological consultation to pick and exclude patients with increases intracranial tention.

Pre-operative preparation mainly carbonic anhydrase inhibitor (acetazolamide therapy) to reduce intracranial tension particularly in long standing cases.

\section{Operative technique:}

Under general hypotensive anesthesia with the table head elevated, nasal packing by local decongestant for five minutes was done. Then a stepwise procedure tailored for each patient according to the side and location of the defect. All patients having their defects in the ethmoid roof ranging between anterior and posterior ethmoids, cribriform plate, lateral lamella and fovea. So in all patients complete ethmoidectomy and subtotal middle turbinectomy were done to optimize exposure of the defect Fig. (1). Intrathecal fluorescein dye injection was performed in some cases as ahelpful way to identify the leak Fig. (2). Identifying and localizing the defect may needs non hypotensive anesthesia and head low down for some minutes. Creating raw area around the defect is an essential step in all patients by removal of mucosa from underlying bone. Fascialata Fig. (3), abdominal fat, rotation septal or turbinate flaps were used, different grafting and rotation flap techniques and their details are not the scope of this study. After sealing the defect and insuring that there is no leak, patients have been divided into two equal groups of 7 patients each. Group A and group B. In group A, packing of the nasal cavity by merocel was done, whoever in group B, before nasal packing by merocel we have used a special pack directly put on the grafted area. The special pack was composed of a silastic sheet $1 \mathrm{~mm}$ thickness over the graft or flap directly and a second layer of rectangular piece of merocel (finger like) $1 \mathrm{~cm}$ by $2 \mathrm{cmms}$ dimensions. Both the silastic and the merocel piece were marked by threads to be plastered over the nasal dorsum away from the thread of the nasal cavity merocel pack. After application of the merocel finger we make it swollen by antibiotic drops then we proceed to put the nasal cavity $10 \mathrm{cmms}$ merocel pack soaked by antibiotic ointment and swollen by normal saline or decongestant solution.

Smooth recovery was essential to avoid straining and sudden increase in intracranial tension.

Post-operative management: Parenteral antibiotics and oral analgesia for three days, then nasal packs were removed in all patients after three days of surgery. Systemic oral antibiotic prophylaxis and Carbonic anhydrase inhibitors were maintained for two weeks plus potassium preparations to avoid hypokalemia.

In group B, patients came weekly visits for three weeks to change the local merocel finger like packendoscopically in the office by a new clean sterile one which was marked again by thread and swollen by antibiotic drops. In the last visit (after three weeks) the silastic sheet was removed endoscopically with no more packs.

Monthly visits for endoscopic assessment have been done routinely for 6 to 12 months.

\section{Results}

In group $\mathrm{A}$, the operative time ranged from 2 to 2.5 hours with a mean of 1.8 hours. Blood loss has a range of 78-210 ccms with a mean of 155 ccms. In group B, the operative time ranged from 2.3 to 2.9 hours with a mean of 2.1 hours. Blood loss has a range of $90-260 \mathrm{ccms}$ with a mean of $195 \mathrm{ccms}$. Hospitalization was one day in all patients with discharge in the second post-operative day. As regards complications, there were no major complications in the form of injury to important adjacent structures or massive hemorrhage or postoperative meningitis. Return to normal life activity or work was possible in all patients after 10 days. As regards the final outcome, all patients were doing well throughout the follow-up period. As regards the recurrence in group $\mathrm{A}$, recurrence in 4 patients, two recurrences after six months and two after one year. In group B, there was one recurrence after 12 months. Regarding the recurrent cases in group A, revision repair has been done to two patients by the special packing technique and the other two patients were lost in the follow-up. The re operated patients are doing well till the date of writing. The recurrent case in group B was referred for neurosurgical consultation. 


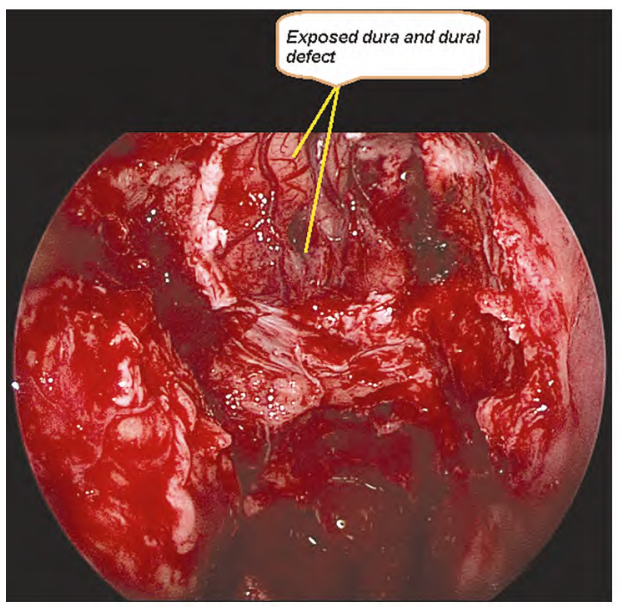

Fig. (1): Skull base defect and exposed dura.

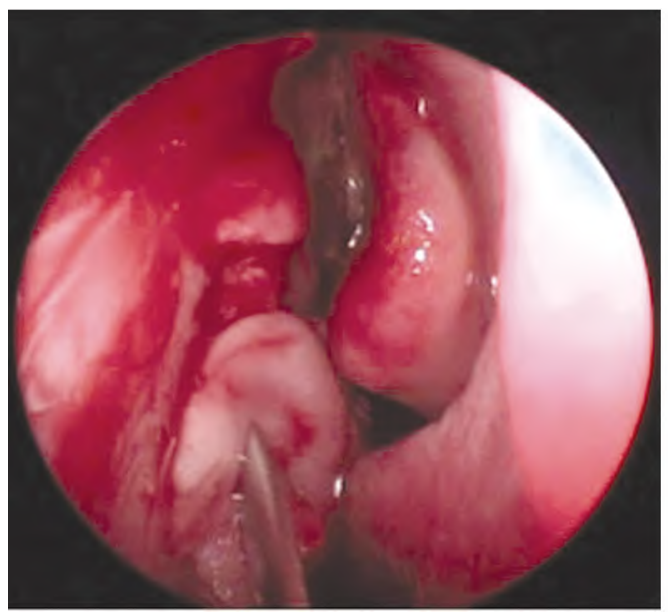

Fig. (3): Facialata graft.

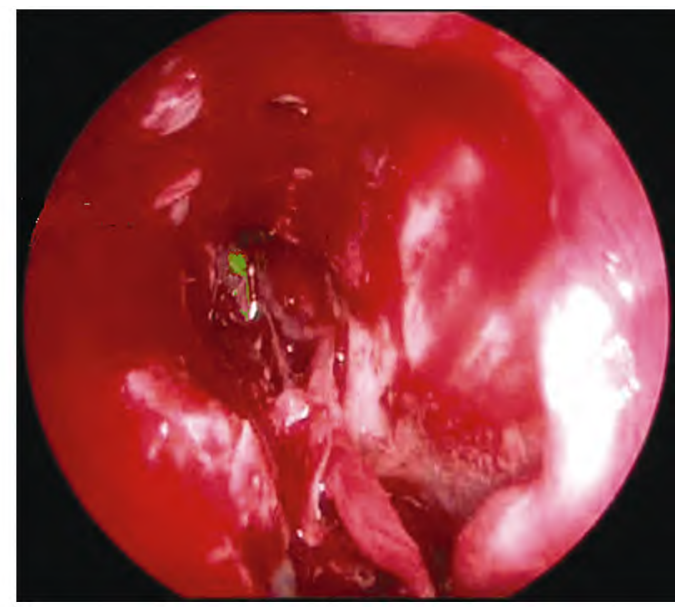

Fig. (2): Appearance of flourescin dye.

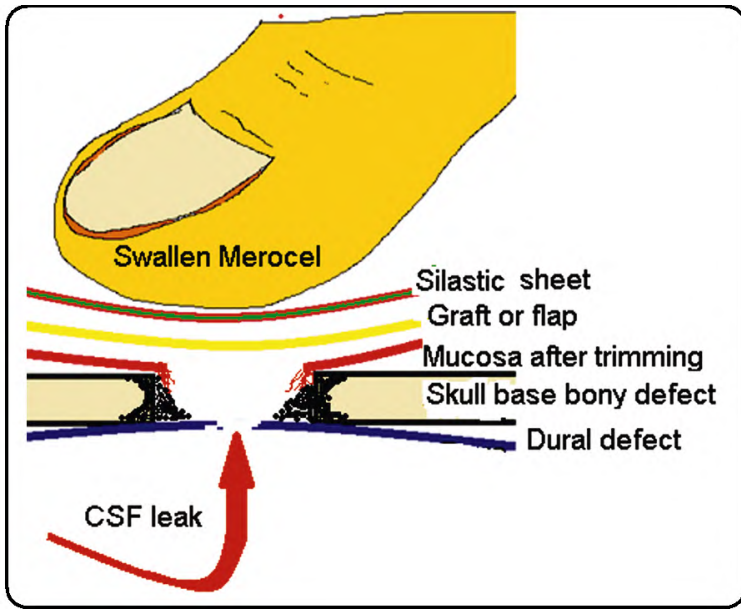

Fig. (4): Swallen merocel exerting pressure like a thumb.

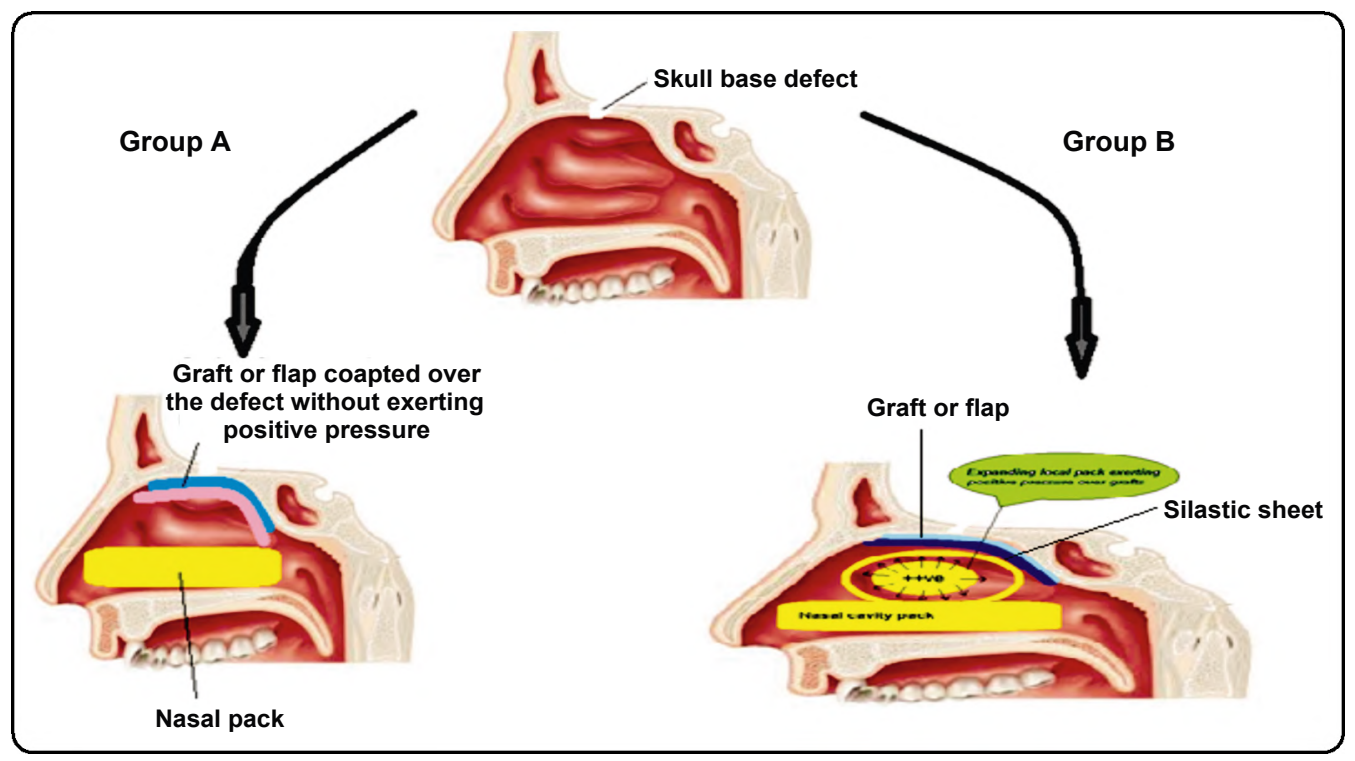

Fig. (5): Packing in both groups. 


\section{Discussion}

Spontaneous Cerebrospinal Fluid (CSF) rhinorrhea represents an important clinical entity that is being observed with increasing prevalence, ranging from 14 to 55\%. Proper endoscopic repair with healthy vascularized flaps and grafts are essential to overcome the normal CSF pressure until healing process to complete [9].

The normal CSF pressure, measured at Lumbar Puncture (LP), is $100-180 \mathrm{~mm}$ of $\mathrm{H} 2 \mathrm{O}(8-15 \mathrm{mmHg})$ with the patient lying on the side and $200-300 \mathrm{~mm}$ with the patient sitting up [10,11].

Boyle's law, also referred as Boyle-Mariotte law is an experimental gas law states that the absolute pressure exerted by a given mass of an ideal gas is inversely proportional to the volume it occupies if the temperature and amount of the gas remain unchanged within a closed system. Mathematically, Boyle's law can be stated as:

$\{P V=k\}$ Pressure multiplied by volume equals some constant $\{\mathrm{k}\}$ where $\mathrm{P}$ is the pressure of the gas, $\mathrm{V}$ is the volume of the gas, and $\mathrm{k}$ is a constant [12].

If we apply normal saline to dry merocel, it increase in size three or four times. So, if we insert a piece of dry merocel with dimensions nearly equal to the area opposite the grafted defect $(, 5 \mathrm{~cm}$ by $1 \mathrm{~cm}$ by $2 \mathrm{cms}$, volume of $1 \mathrm{ccm}$ ), and then wet it by saline, it will swell to acquire a volume about 4 times its original volume, whoever the small limited cavity will prevent its size to increase. This will result in a stored static potential energy in its peripheryin the form of pressure four times the atmospheric pressure according to Boyle' law which will exceeds the normotensive CSF pressure (8$15 \mathrm{mmHg}$ ) [11]

For a graft or flap to stop a normotensive CSF leak, it needs to exert a static potential energy or force equal or more than CSF pressure. Any graft, flap or non expanding gauze pack when fill the dead space and takes the shape of this space will exert nearly zero force at its periphery so may be unable to prevent CSF leak, whoever if this graft was pushed by an expanding pack (its size is bigger than the space) like sponge or merocel, so it will exert a potential force sufficient to overcome the normal CSF pressure preventing its leak.

In this study we utilized the potential energy stored in the wet merocel finger like piece about $1 \mathrm{cmm}$ by 1.5 to $2 \mathrm{cmms}$ (when dry) as a local pack directly over the grafted defect with a silastic sheet in between, this merocel finger like piece will be swollen after wetting by an antibiotic drops to acquire a size larger than the space it fill, so it will exert a considerable peripheral force applied to the silastic sheet and the graft under it. Both the merocel finger like pack and the silastic sheet were marked by silk threads. After one week of surgery we exchange the merocel local pack endoscopically in the office. It will be pulled by its silk thread and discarded to be replaced by a clean sterile one with the same dimensions. The silastic sheet protects the grafts and flaps from avulsion during merocel withdrawal. The silastic sheet also can be pulled by its marked thread to be washed and cleaned by normal saline and repositioned again over the grafted area then we proceed to place the new finger like merocel piece with the same size. Now we wet the merocel by antibiotic drops to make it swollen. The threads of both the silastic sheet and merocel will be plastered over the nasal dorsum. This scenario will be repeated exactly in the second post-operative week. In the third week final removal of the merocel pack and the silastic sheet. This local packing mechanism acts like a thumb pressing continually, Figs. $(4,5)$ creating persistent low grade positive pressure over the graft, blocking any leak until proper adhesions and healing to be established and at the same time the pressure will not interfere with blood supply and capillary circulation at the area of healing.

The merocel should be replaced weekly by a new sterile one for two reasons, the first being the wet swollen merocel become gradually hard and loose its expandable force with gradual decrease in its peripheral potential force. The second reason, is to avoid local infection and granulations.

\section{Conclusion:}

In this study, we have confirmed the great value of local special packing over the grafted area utilizing the effect of stored potential power in the wet merocel finger like pack and intervening silasticsheet to protect the flap and minimizing reaction and granulations. This mechanism makes the surgeon as if pressing by his thumb over the graft and rotation flaps gently throughout the healing period. Recurrence after this tight mechanism should alert the surgeon to revise his primary decision and to consider intracranial hypertension with plans for diversion or shunting procedures beside the repair.

\section{Recommendation:}

I recommend to fulfill the criteria ofintraoperative pressure local packing and during pack replacement post-operatively to obtain the required sustained pressure over the grafted area optimizing the success rate. 


\section{References}

1- KESHRI A., JAIN R., MANOGARAN R.S., BEHARI S., KHATRI D. and MATHIALAGAN A.: Management of Spontaneous CSF Rhinorrhea: An Institutional Experience. J. Neurol. Surg. B Skull Base. Oct., 80 (5): 493-9. doi: 10.1055/s-0038-1676334. Epub 2018 Dec 5, 2019.

2- KREATSOULAS D.C., SHAH V.S., OTTO B.A., CARRAU R.L., PREVEDELLO D.M. and HARDESTY D.A.: Surgical outcomes of the endonasal endoscopic approach within a standardized management protocol for repair of spontaneous cerebrospinal fluid rhinorrhea. J. Neurosurg., Feb. 28: 1-7. doi: 10.3171/2019.12.JNS192891, 2020.

3- ZHANG S.N., JIANG Y., YU L.G., ZHAO L.J., LI L.L., ZHANG C.Y., XU W.R. and LI N.: [Clinical analysis of transnasal endoscopic repair of cerebrospinal fluid rhinorrhea]. Lin. Chung Er. Bi Yan Hou Tou Jing Wai Ke Za Zhi., Dec., 33 (12): 1189-95; 1199. doi: 10.13201/ j.issn.1001-1781.2019.12.018, 2019.

4- KIM-ORDEN N., SHEN J., OR M., HUR K., ZADA G. and WROBEL B.: Endoscopic endonasal Repair of Spontaneous Cerebrospinal Fluid Leaks Using Multilayer Composite Graft and Vascularized Pedicled Nasoseptal Flap Technique. Allergy Rhinol (Providence). Nov. 13, 10: 2152656719888622 . doi: $10.1177 / 2152656719888622$. eCollection 2019 Jan.-Dec., 2019.

5- BABU A.R., PRAKASH B.G., KADLIMATTI V.I., SANDHYA D. and KAMATH S.: Contrasting Surgical Management of CSF Leak from Lateral Recess of Sphenoid Sinus and Its Surgical Outcomes: Our Experience. Indian J. Otolaryngol. Head Neck Surg., Dec., 71 (4): 531-6. doi: 10.1007/s12070-019-01715-w. Epub. 2019 Jul. 26, 2019.
6- DAI J.B., DEL SIGNORE A.G., GOVINDARAJ S., BEDERSON J.B., ILORETA A.M.C. and SHRIVASTAVA R.K.: Investigation of Skull-Based Cerebrospinal Fluid Leak Repair: A Single-Institution Comprehensive Study of 116 Cases Over 10 Years. World Neurosurg., Mar., 135: e1-e11. doi: 10.1016/j.wneu.2019.09.133. Epub 2019 Oct. 8, 2020.

7- ALLENSWORTH J.J., ROWAN N.R., STORCK K.A., WOODWORTH B.A. and SCHLOSSER R.J.: Endoscopic repair of spontaneous skull base defects decreases the incidence rate of intracranial complications. Int. Forum. Allergy Rhinol., Oct., 9 (10): 1089-96. doi: 10.1002/ alr.22399. Epub 2019 Aug. 12, 2019.

8- BARR J., NI J., McGINN J. and GOYAL N.: Topical intranasal fluorescein to localize a cerebrospinal fluid leak: A demonstration. Am. J. Otolaryngol., Feb. 11: 102413. doi: 10.1016/j.amjoto.2020.102413, 2020.

9- R. BOYLE: A Defence of the Doctrine Touching the Spring and Weight of the Air, (London: Thomas Robinson, 1662).

10- CHARLES WEBSTER: "The discovery of Boyle's law, and the concept of the elasticity of air in seventeenth century," Archive for the History of Exact Sciences, 2 (6): 473-7, 1965.

11- CHARLES WEBSTER: "Richard Towneley and Boyle's Law," Nature, 197 (4864): 226-8, 1963.

12- TANG C., ZHU J., FENG K., YANG J., CONG Z., CAI X., QIAO L. and MA C.: Successful Treatment of Spontaneous Cerebrospinal Fluid Rhinorrhea With Endoscopic Third Ventriculostomy and Lumboperitoneal Shunt: A Case Report. Front Neurosci., Jan. 31, 14: 57. doi: 10.3389/ fnins.2020.00057, 2020.

\title{
الدور المحورى لطريقة حشو الآنف

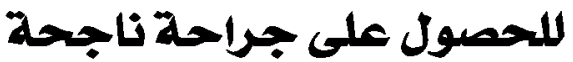 \\ فى حالات تسرب السائل النخاعى من الآنف
}

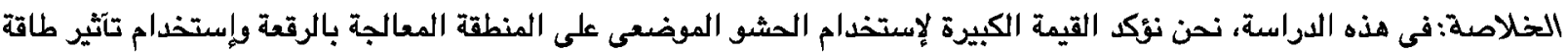

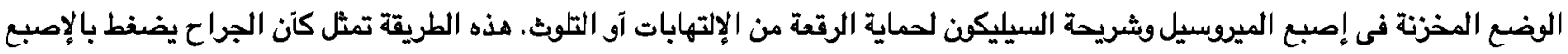

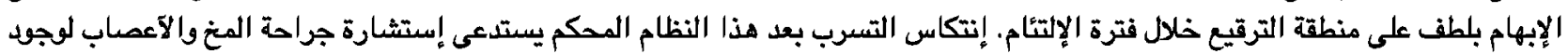 \\ إحتمالية زيادة ضفط السائل النخاعى.
}

